\title{
A commercial immune modulating feed additive restores L-selectin and CCL5 expression following dexamethasone treatment of murine immune cells in a MyD88-dependent manner
}

\author{
R. J. Ortiz-Marty, ${ }^{*}$ A. Lewandowski, ${ }^{\text {}}$ J. D. Chapman, $†$ and I. Kanevsky-Mullarky*1 \\ *Mastitis and Immunology Laboratory, Dairy Science Department, Virginia Polytechnic Institute and State University, Blacksburg 24061 \\ †Phibro Animal Health Corporation, Teaneck, NJ 07666
}

\begin{abstract}
Bovine mastitis costs the dairy industry billions of dollars every year and presents a health challenge in dairy facilities. Immunosuppressive effects of the periparturient period increase the incidence of mastitis. During this time, cattle experience an elevation in circulating cortisol, which reduces polymorphonuclear cell function and ability to clear infection. OmniGenAF (OMN; Phibro Animal Health, Teaneck, NJ) is an immunomodulatory feed additive that alters gene expression and is used to reduce rates of mastitis. We hypothesized that OMN restores gene expression during periods of immune stress through inhibiting the suppressive effects of glucocorticoid receptor signaling on Toll-like receptor signaling. To test our hypothesis, wild-type (WT) or MyD88 knockout mice were supplemented with OMN and challenged with lipopolysaccharide following dexamethasone (Dex) treatment. Polymorphonuclear cell and macrophage RNA was isolated from intraperitoneal lavages and analyzed for gene expression profiles. Treatment of mice with Dex suppressed expression of L-selectin and CCL5 as compared with phosphate-buffered saline treatment of WT mice. Expression of L-selectin and CCL5 was significantly reduced with Dex treatment in control-fed but not OMN-supplemented WT mice. The protective effect of OMN supplementation on L-selectin expression during Dex treatment was abolished in MyD88 knockout mice. These results suggest that OMN supplementation restores responses of certain genes suppressed by Dex in immune cells in a MyD88-dependent manner. Future research will determine the specific Toll-like receptors, transcription factors, and biochemical properties of OMN that restore gene expression in immunosuppressed cells.
\end{abstract}

Key words: lipopolysaccharide, periparturient period, innate immune function, dietary immunomodulation

Received July 26, 2016.

Accepted April 2, 2017.

${ }^{1}$ Corresponding author: isisk@vt.edu

\section{INTRODUCTION}

Bovine infectious mastitis is an economic challenge for the dairy industry. Incidences of mastitis increase during the periparturient period due, in part, to changes in stress hormones and function of neutrophils (PMNL; Cai et al., 1994; Burton et al., 1995; Burton et al., 2005). At time of parturition, an increase in serum cortisol (Jacob et al., 2001) correlates to decreased expression of glucocorticoid receptor (GR)- $\alpha, C D 18$, and L-selectin genes in bovine blood PMNL (Burton et al., 1995, 2005; Preisler et al., 2000). Following parturition, circulating cortisol concentrations return to normal, but the suppressive effects on bovine PMNL are still evident (Preisler et al., 2000; Burton et al., 2005). Means of combating immunosuppression would decrease rates of infection during the periparturient period.

OmniGen-AF (OMN; Phibro Animal Health, Teaneck, NJ) is a proprietary patented immunomodulatory feed supplement that alters PMNL gene expression (Wang et al., 2009). Supplementation of sheep (Wang et al., 2007) and heifers (Ryman et al., 2013) with OMN during immunosuppressive conditions increased expression of L-selectin by PMNL, suggesting a potential restorative effect on PMNL migration. Furthermore, supplemented heifers had monocytes that were better able to engulf Staphylococcus aureus $(P<0.05)$ and had significantly less mammary edema after calving compared with unsupplemented controls (Nace et al., 2014). In murine studies, feeding of supplemented chow for 2 wk before infections with Streptococcus uberis, $S$. aureus, and Escherichia coli resulted in significantly less bacterial DNA in mammary tissue as compared with feeding of control chow (Rowson et al., 2011). These data suggest that OMN affects PMNL gene expression and function; however, the signaling pathways involved are unknown.

Mammalian cell membranes express toll-like receptors (TLR), which recognize pathogen-associated membrane patterns to induce inflammatory immune responses and clear pathogens. Interestingly, several transcription factors are downstream of TLR and GR 


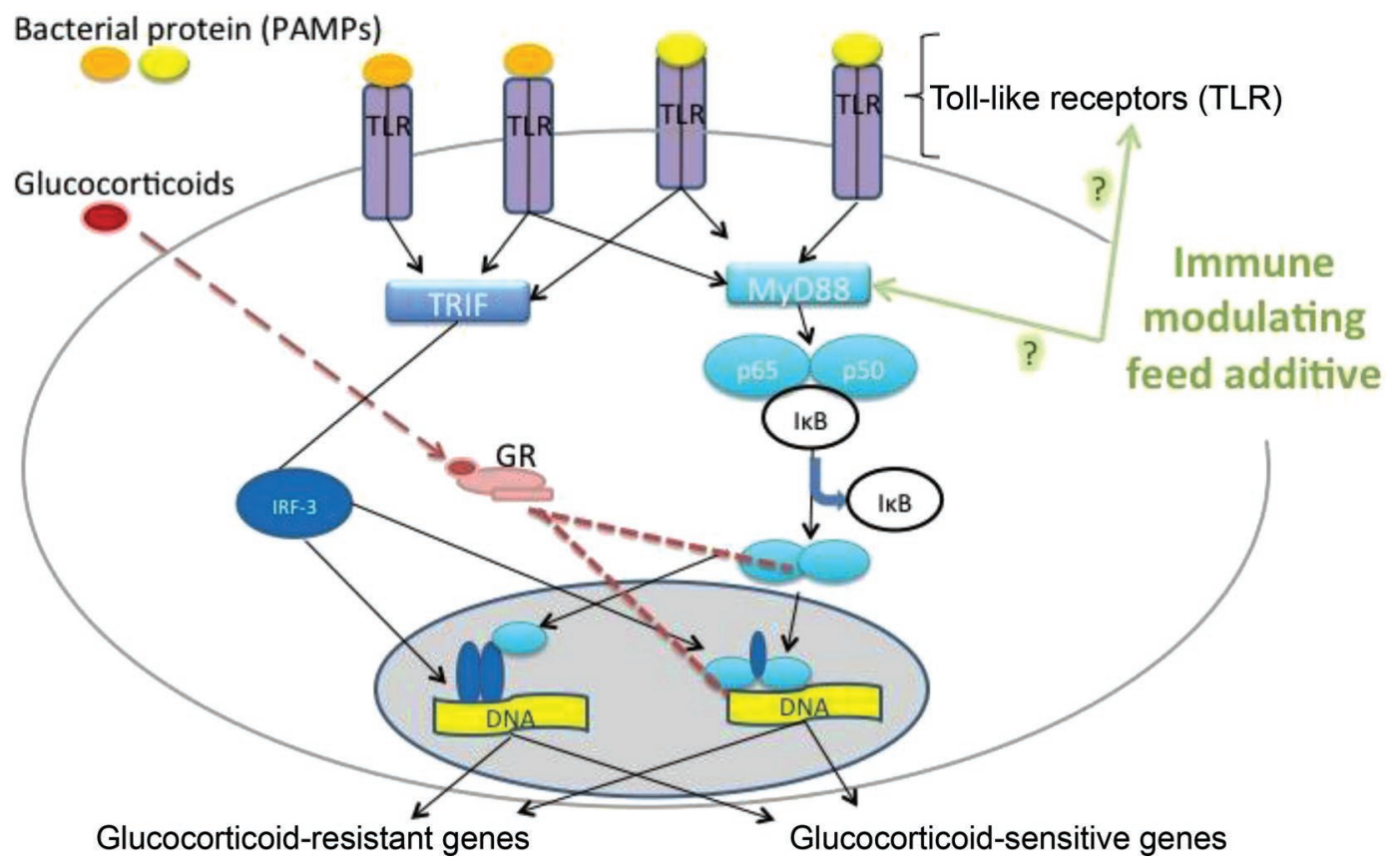

Figure 1. Potential role for restoration of toll-like receptor (TLR) signaling through inhibition of glucocorticoid receptor (GR) signaling. Immune genes can be sensitive to glucocorticoid modification depending on activated TLR signaling pathways (MyD88 or TRIF; Ogawa et al., 2005). We propose that immunomodulatory feed additives may counter-regulate glucocorticoid sensitive gene expression by modulation of TLR activities. PAMP = pathogen-associated molecular pattern; P65 = nuclear factor NF-kappa-B p65 subunit; TRIF = TIR-domain-containing adapter-inducing interferon- $\beta$; P50 = nuclear factor kappa B subunit 1 ; IRF-3 = interferon regulatory factor 3 ; iKB $=$ NFKB inhibitor alpha.

that potentially cross-regulate immune responses in PMNL (Ogawa et al., 2005; Glass and Ogawa, 2006). We hypothesized that OMN restores gene expression during periods of immune stress through inhibiting the suppressive effects of GR signaling on TLR signaling (Figure 1). Through understanding the mechanisms by which OMN affects immune cell gene expression, new disease targets may be identified.

\section{MATERIALS AND METHODS}

\section{Mice and Supplementation}

Five-week-old C57BL/6 wild-type (WT) and MyD88 knockout (KO), pathogen-free mice (Jackson Laboratories, Bar Harbor, ME) were used. Mice were housed in groups of 5 with unlimited access to water and chow for a minimum of 2 wk until the time of harvest. OmniGen-AF was provided by Phibro Animal Health and incorporated into pelleted feed by Teklad Lab Animal Diets (Harlan Laboratories Inc., Madison, WI) at a concentration of $5 \mathrm{~g} / \mathrm{kg}$ in the 2018 Teklad Global, 18\% protein rodent diet. Mice were fed regular chow $(\mathbf{C O N})$ or chow with incorporated OMN ad libitum and weights were monitored. All procedures were approved and carried out in accordance with the Institutional Animal Care and Use Committee of Virginia Tech.

\section{Immunosuppression and LPS Challenge}

All injectable materials were purchased from SigmaAldrich (St. Louis, MO), unless otherwise noted. To induce immunosuppression, mice were injected with $0.5,1.0$, or $3 \mathrm{mg} / \mathrm{kg}$ of dexamethasone (Dex) i.p. 12 $\mathrm{h}$ before euthanization. Immune cells were recruited to the peritoneal cavity by i.p. injection of aged (at least $1 \mathrm{mo}) 3 \%$ thioglycollate broth $(1 \mathrm{~mL}) 4,12$, or $18 \mathrm{~h}$ before harvest. The LPS $(100 \mu \mathrm{g}, \mathrm{O} 55$ :B5 Escherichia coli strain) diluted in PBS was injected i.p. 2 to $4 \mathrm{~h}$ before harvest.

\section{Intraperitoneal Lavage}

Mice were euthanized with $\mathrm{CO}_{2}$ and the abdominal area was sprayed with $70 \%$ ethanol. The epidermis was cut and separated to expose the peritoneal sac. Five milliliters of ice-cold $1 \times$ Dulbecco's PBS (Invitrogen, Carlsbad, CA) with $10 \mathrm{~m} M$ EDTA (Calbiochem, San Diego, SA) was injected i.p., massaged within the peritoneal sac, extracted, and kept on ice.

Concentration of PMNL and macrophages (PMNL/ $\mathrm{Mac})$ in i.p. lavage was determined after cells were stained using murine-specific antibodies against Ly6 (PMNL) and CD14 (Mac; Pharmigen, Becton, Dickinson and Co., Franklin Lakes, NJ) according to manu- 
Table 1. Primer/probe sets for inflammatory murine gene expression analysis

\begin{tabular}{lll}
\hline Primer/probe set & Reference number & Company \\
\hline RPL19 & Mm02601633_g1 & Applied Biosystems, Foster City, CA \\
YWHAZ & Mm01158416_g1 & Applied Biosystems, Foster City, CA \\
GR-1 & Mm00433832_m1 & Applied Biosystems, Foster City, CA \\
L-selectin & Mm00441291_m1 & Applied Biosystems, Foster City, CA \\
CCL5 (RANTES) & Mm01302427_m1 & Applied Biosystems, Foster City, CA \\
\hline
\end{tabular}

facturer's recommendation. A total of 10,000 events were collected per sample and percentages of cells were determined by flow cytometry (Accuri C6, Becton, Dickinson and Co.) and analyzed using FlowJo Software (TreeStar, Ashland, OR).

\section{RNA Isolation}

The i.p. lavage samples were centrifuged at $100 \times g$ at $4^{\circ} \mathrm{C}$ for $10 \mathrm{~min}$. Supernatants were discarded and pellets were resuspended in $5 \mathrm{~mL}$ of ice-cold PBSE (PBS $+1 \mathrm{~m} M$ EDTA) before centrifugation. Pellets were suspended in $5 \mathrm{~mL}$ of red blood cell lysis buffer $(8 \%$ $\mathrm{NH}_{4} \mathrm{Cl}, 0.01 M$ EDTA, pH 7.4) vortexed, and placed on ice for $10 \mathrm{~min}$ before centrifugation at $100 \times g$ at $4^{\circ} \mathrm{C}$ for $10 \mathrm{~min}$. Supernatants were discarded and pellets were suspended in $600 \mu \mathrm{L}$ of RLT buffer (Qiagen, Valencia, CA) containing $10 \mu \mathrm{L}$ of $\beta$-mercaptoethanol (Sigma Aldrich) per milliliter of RLT buffer. Samples were stored at $-80^{\circ} \mathrm{C}$ until further use.

\section{Reverse Transcriptase Real-Time PCR for mRNA Quantification}

Total RNA was isolated from samples using RNeasy Mini Kit (Qiagen) as indicated by manufacturer. Complimentary DNA was synthesized from sample mRNA $(2.2 \mu \mathrm{g})$ by heating the sample at $70^{\circ} \mathrm{C}$ for $10 \mathrm{~min}$ with $250 \mathrm{ng}$ of random primers (Invitrogen). Samples were cooled to $4^{\circ} \mathrm{C}$ and centrifuged at $350 \times g$ for $30 \mathrm{~s}$ at $4^{\circ} \mathrm{C}$. Samples were brought to $19.5 \mu \mathrm{L}$ with a solution containing $20.5 \%$ (vol) $5 \times$ buffer, $10 \%$ (vol) $0.1 M$ dithiothreitol, $5 \%$ (vol) $10 \mathrm{~m} M$ deoxyribonucleotides (VWR, Suwanee, GA), and $2.5 \%$ (vol) Superscipt II (reverse transcriptase). All reagents were purchased from Invitrogen unless indicated otherwise. Samples were incubated at $42^{\circ} \mathrm{C}$ for $50 \mathrm{~min}$ followed by $70^{\circ} \mathrm{C}$ for 15 min to deactivate the reverse transcriptase. Samples were brought up to $10 \mathrm{ng} / \mu \mathrm{L}$ of cDNA with DNase/ RNase-free water (Qiagen).

Primers and probes mixes (Table 1) were purchased from Applied Biosystems (Foster City, CA). The TaqMan Universal PCR Master Mix (Applied Biosystems) and the ABI 7300 Real-Time PCR System (Applied Biosystems) were used for analysis. The final volume for analysis was $25 \mu \mathrm{L}$, containing $300 \mathrm{n} M$ of both forward and reverse primers (Integrated DNA Technologies, Coralville, IA), $100 \mathrm{n} M$ of 6-carboxyfluorescein probe (Biosearch Technologies Inc., Novato, CA), 2× TaqMan Universal PCR Master Mix (Applied Biosystems), and $50 \mathrm{ng}$ of cDNA. Samples were heated at $50^{\circ} \mathrm{C}$ for $2 \mathrm{~min}, 95^{\circ} \mathrm{C}$ for $10 \mathrm{~min}, 95^{\circ} \mathrm{C}$ for $15 \mathrm{~s}$ for 40 cycles, and cooled at $60^{\circ} \mathrm{C}$ for $1 \mathrm{~min}$. Sample cycle threshold $(\mathbf{C t})$ values were exported for analysis.

\section{Statistical Analysis}

Data were analyzed and graphed using GraphPad Prism Version 4.03 (La Jolla, CA). Gene of interest $\mathrm{Ct}$ was compared with the $\mathrm{Ct}$ value of stable housekeeping gene, RPL19 (ribosomal protein ligand 19), as determined by preliminary studies for gene consistency, to obtain the $\Delta \mathrm{Ct}$. Treatment $\Delta \mathrm{Ct}$ values were compared with PBS control $\Delta \mathrm{Ct}$ values to obtain $\Delta \Delta \mathrm{Ct}$, which was used to calculate fold induction $\left(2^{-\Delta \Delta \mathrm{Ct}}\right)$ for figures. Statistical analysis was conducted on samples $\Delta \Delta \mathrm{Ct}$ values. For evaluating significant differences of treatment in WT animals, a 1-way ANOVA with a Dunnett's posttest was used to compare with PBS controls only. Significance of treatment and diet was determined using 2-way ANOVA with a Tukey's posttest. Significance was considered at $P<0.05$.

\section{RESULTS}

\section{Gene Regulation in Immune Cells by Dex}

Immune cells were recruited to the peritoneal cavity of WT mice with $3 \%$ thioglycollate to identify optimal time conditions for collection. As thioglycollate recruits both PMNL and Mac, flow cytometry was used to confirm recruitment and enumerate both cell populations (Figure 2). Percentages of cells expressing CD14 (Mac) and Ly-6 expression (PMNL) in i.p. lavage was compared at 4, 12, and $18 \mathrm{~h}$ postinjection. Numbers of PMNL were higher than those of Mac at all time points (Figure 2). However, the 12-h time point provided the greatest number of PMNL and highest ratio of PMNL to Mac and was used for subsequent experiments.

To determine optimal conditions for assessing immune suppression and the effect of OMN supplementation in 
a mouse model, a Dex dose response was completed. Injection of LPS had no significant effect on gene expression of $G R$-1, decreased expression of L-selectin ( $P$ $<0.01$ ), and increased expression of CCL5 (RANTES) $(P<0.01)$ in murine peritoneal PMNL/Mac as compared with PBS controls (Figure 3). Injection of Dex alone resulted in significant decrease of L-selectin gene expression at all doses, and CCL5 at $3 \mathrm{mg} / \mathrm{kg}(P<$ $0.01)$. Interestingly, gene expression of $G R-1$ increased following LPS challenge and treatment with 0.5 and $1.0 \mathrm{mg} / \mathrm{kg}$ of Dex, but did not differ from PBS controls at $3.0 \mathrm{mg} / \mathrm{kg}$ of Dex. Treatment with $3.0 \mathrm{mg} / \mathrm{kg}$ of Dex and LPS resulted in a significant decrease in gene expression of L-selectin, but an increase in expression of $C C L 5$ as compared with treatment with PBS only. Subsequent experiments were conducted using $3.0 \mathrm{mg} /$ $\mathrm{kg}$ of Dex in LPS-treated mice.

\section{Feed Additive Restores Dex-Induced Gene Suppression Through MyD88 Pathway}

Murine PMNL were isolated from WT or MyD88 $\mathrm{KO}$ mice fed chow unsupplemented $(\mathrm{CON})$ or supplemented with OMN in their diet for 2 wk. Mice were injected with Dex or PBS and challenged with LPS, as indicated in Figure 4. Despite the decrease in fold expression of $G R-1$ in PMNL/Mac from WT mice treated with LPS and Dex as compared with LPS only, this difference was not significant $(P=0.07)$. Similarly, the increase in fold expression for $G R-1$ following treatment with LPS and Dex in PMNL/Mac from WT mice fed $\mathrm{OMN}$ as compared with $\mathrm{CON} \operatorname{diet}(P=0.14)$ was not significant (Figure 4A). Interestingly, PMNL/Mac from the MyD88 KO mice fed OMN diet expressed significantly less $G R-1(P<0.01)$ compared with CON fed mice (Figure 4B) following LPS treatment. The PMNL/Mac from the MyD88 KO mice fed the OMN diet and treated with LPS expressed significantly less $G R-1(P<0.05)$ compared with CON fed mice (Figure $4 \mathrm{~B})$ treated with LPS and Dex.

Expression of L-selectin was significantly lower in PMNL/Mac from CON-fed mice treated with LPS and Dex as compared with LPS only (Figure 4C; $P<$ $0.005)$. However, we found no significant difference in OMN-fed mice, suggesting a role for diet in restoring the immunosuppressive effects of Dex treatment. The LPS and Dex induced significantly $(P=0.01)$ greater expression of L-selectin in PMNL/Mac from OMN fed as compared with expression in PMNL/Mac from LPSand Dex-treated CON-fed WT PMNL/Mac (Figure $4 \mathrm{C})$. The PMNL/Mac from the WT mice fed the OMN diet and treated with LPS expressed significantly more L-selectin $(P<0.01)$ compared with $\mathrm{CON}$-fed mice (Figure 4C) treated with LPS and Dex. Expression of
A

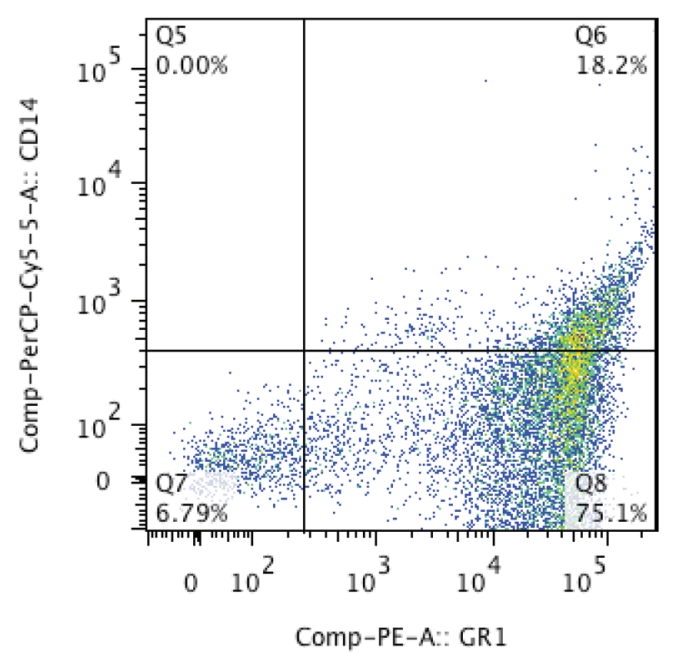

B

\begin{tabular}{|c|c|c|c|}
\hline Thioglycollate & $\begin{array}{c}\text { PMNL } \\
\text { (no. of cells) }\end{array}$ & $\begin{array}{c}\text { Mac } \\
\text { (no. of cells) }\end{array}$ & $\begin{array}{c}\text { PMNL:Mac } \\
\text { ratio }\end{array}$ \\
\hline $4 \mathrm{~h}$ & $5.20 \times 10^{4}$ & $1.70 \times 10^{4}$ & 3 \\
\hline $12 \mathrm{~h}$ & $3.10 \times 10^{7}$ & $7.80 \times 10^{6}$ & 4 \\
\hline $18 \mathrm{~h}$ & $2.70 \times 10^{5}$ & $9.60 \times 10^{4}$ & 3 \\
\hline
\end{tabular}

Figure 2. Comparing murine PMNL with macrophage populations for optimal isolation time. Mice were injected with $3 \%$ thioglycollate at 4,12 , or $18 \mathrm{~h}$ before slaughter and primary murine PMNL and macrophages (Mac) were extracted through intraperitoneal lavage and purified ex vivo. (A) Percentages of cells expressing CD14 (Mac) and Ly6/GR-1 (PMNL) in i.p. lavage collected at $12 \mathrm{~h}$; (B) comparison of PMNL and Mac number [number of cells isolated $\times$ percent cells in lymphocyte gate $\times$ (percent CD14+ or Ly6+, respectively)] in i.p. lavage 4,12 , and $18 \mathrm{~h}$ after injection of thioglycollate in individual mice (shown as representative example). CD14 $=$ CD14 molecule $(\mathrm{CD}=$ cluster of differentiation); Ly6 = lymphocyte antigen 6 complex; GR-1 $=$ glucocorticoid receptor 1 .

L-selectin was significantly lower $(P<0.05)$ in PMNL/ Mac from OMN fed MyD88 KO mice treated with LPS and Dex as compared with CON fed treated with LPS only (Figure 4D).

In both WT (Figure 4E) and MyD88KO (Figure 4F) CON-fed mice, expression of CCL5 was significantly $(P<0.005)$ lower in PMNL/Mac following treatment with LPS and Dex as compared with LPS only. Though no significant decrease in CCL5 expression occurred in PMNL/Mac from WT mice fed OMN treated with LPS and Dex as compared with LPS only (Figure $4 \mathrm{E})$, a significant difference $(P<0.0001)$ remained in MyD88 KO mice (Figure 4F). The PMNL/Mac from the MyD88 KO mice fed the OMN diet and treated with LPS expressed more $G R-1(P<0.005)$ compared with CON-fed mice (Figure $4 \mathrm{~F}$ ) treated with LPS and Dex. Expression of $C C L 5$ was significantly lower $(P<$ 0.0001) in PMNL/Mac from OMN fed MyD88 KO mice 
A

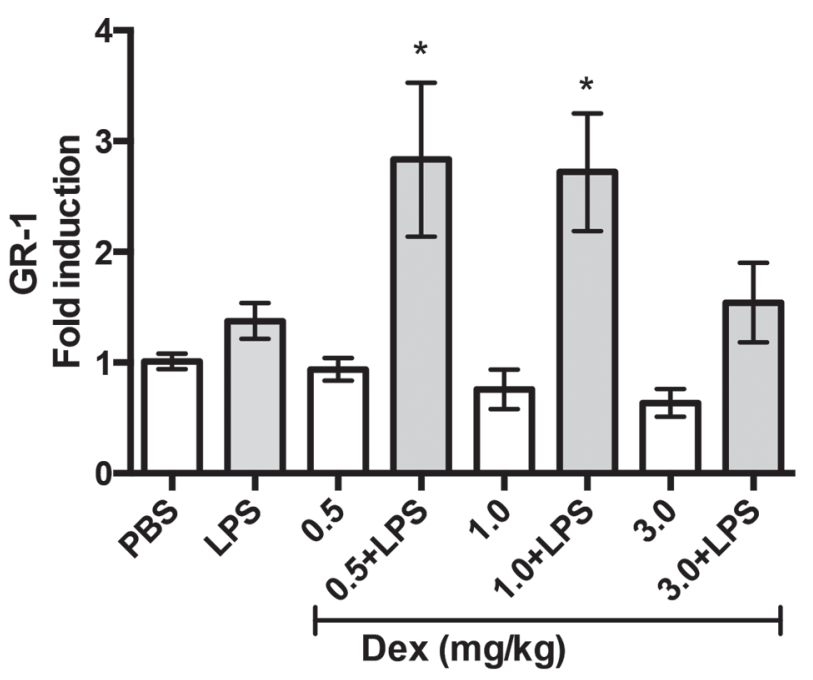

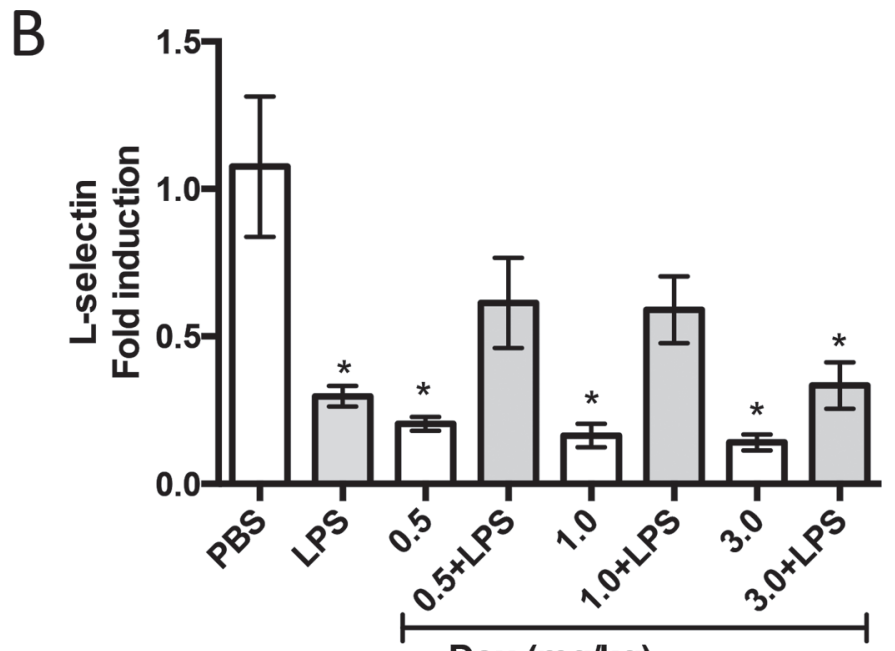

$\operatorname{Dex}(\mathrm{mg} / \mathrm{kg})$

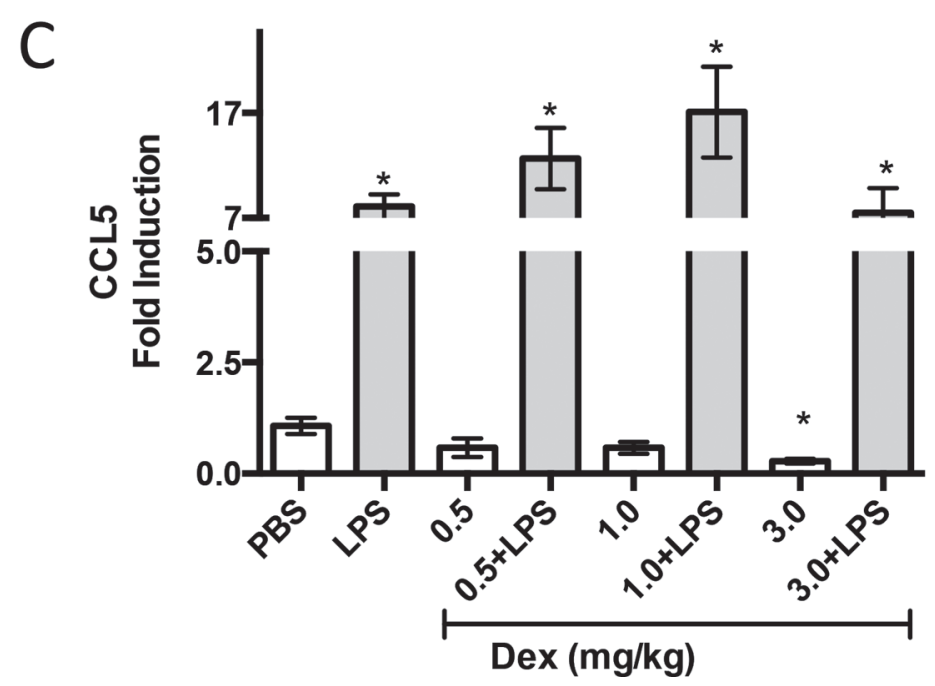

Figure 3. Dexamethasone (Dex) titration for optimal PMNL immunosuppression to LPS challenge. Wild-type mice were injected in the intraperitoneal cavity with $3 \%$ thioglycollate $12 \mathrm{~h}$ before euthanization, increasing concentrations of dexamethasone (Dex; 0.5-3 mg/kg) 12 $\mathrm{h}$ before euthanization, and challenged with $100 \mu \mathrm{g}$ of LPS $2 \mathrm{~h}$ before euthanization. Primary PMNL were extracted through intraperitoneal lavage and expression of glucocorticoid receptor (GR-1; A), L-selectin (B), and CCL5 (C) was determined. Data represents PBS control (white bars), LPS, Dex treatment alone, or Dex treatments with LPS challenge (gray bars). Each treatment was conducted on 5 mice $(\mathrm{n}=5)$. Data were analyzed through a one-way ANOVA with a Dunnett's posttest. Significance difference from PBS is indicated with asterisk $(* P<0.05)$. Error bars represent SEM.

treated with LPS and Dex as compared with CON-fed mice treated with LPS only (Figure 4F).

\section{DISCUSSION}

During the periparturient period, dairy cattle are susceptible to infections due, in part, to the immunosuppressive effects of cortisol on circulating leukocytes (Preisler et al., 2000; Burton et al., 2005). The inhibitory effects of glucocorticoids on PMNL function in periparturient cattle affect expression of membrane receptors and apoptotic genes (Burton et al., 1995,
2005). OmniGen-AF feed additive has a positive effect on gene regulation, resulting in less severe inhibition of gene expression in PMNL (Wang et al., 2009); however, the signaling pathways involved in OMN restoration of PMNL function is undetermined. Our model describes a potential mechanism for glucocorticoid-induced suppression of inflammatory genes in PMNL/Mac and restoration of responses by OMN on genes that could affect immune function and infection rates.

Our data suggest that OMN restores LPS-induced gene suppression of $G R-1$, L-selectin, and CCL5 in a MyD88-dependent manner. Previous work by Ogawa 


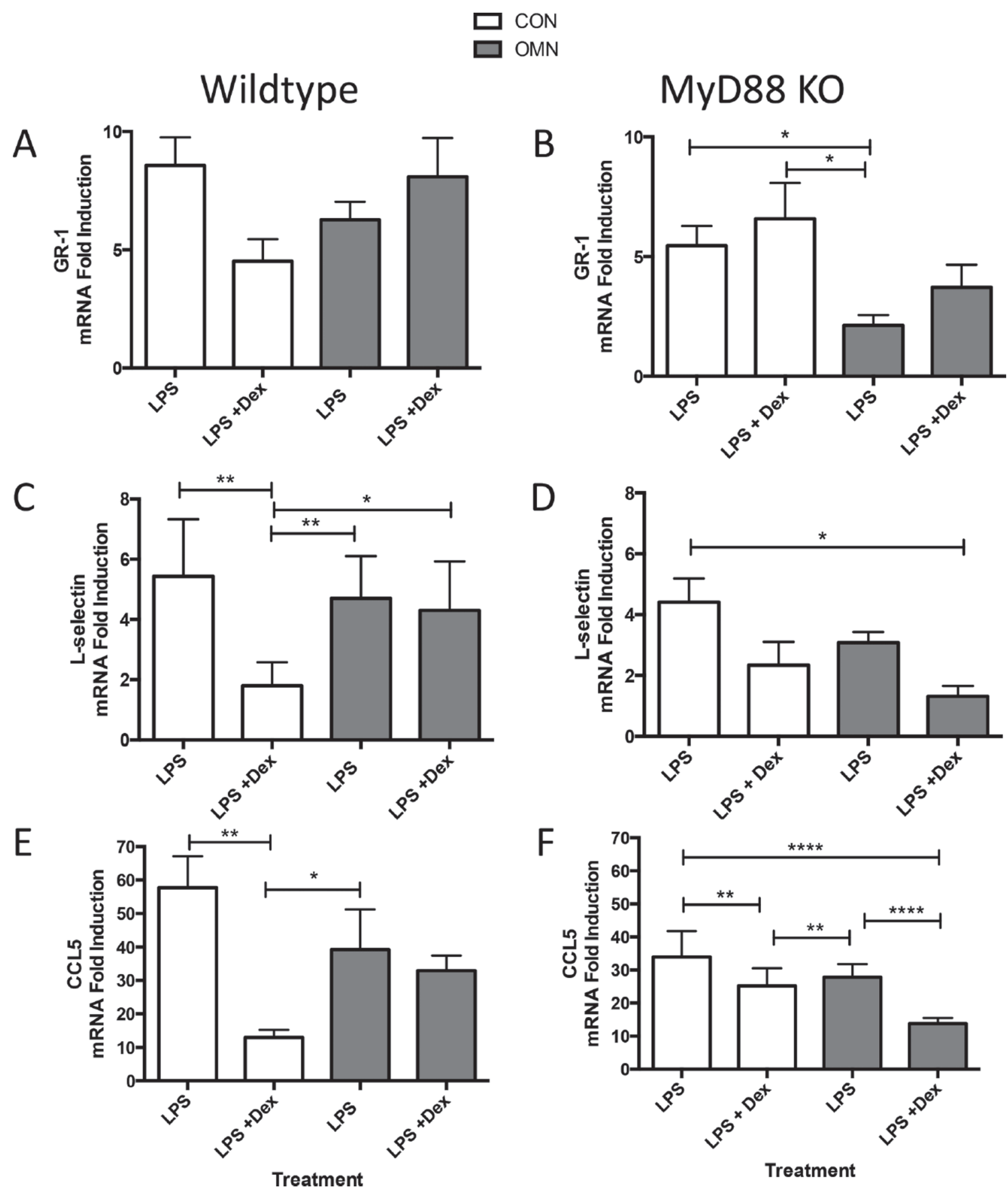

Figure 4. Supplementation of wild-type (WT) and $M y D D 88$ knockout (KO) mice alters gene expression in immune cells following stimulation with LPS or dexamethasone (Dex). Wild type (A, C, and E) and MyD88 KO (B, D, and F) mice were fed unsupplemented (CON) or supplemented (OMN) feed for $2 \mathrm{wk}$. Twelve hours before euthanization, mice were injected with $3 \mathrm{mg} / \mathrm{kg}$ of PBS or Dex in the intraperitoneal cavity. Two hours before euthanization, mice were injected with $100 \mu \mathrm{g}$ of LPS in the intraperitoneal cavity. The PMNL and macrophages (Mac) were collected through intraperitoneal lavage for gene expression analysis of glucocorticoid receptor (GR-1; A and B), L-selectin (C and D), and CCL5 $(\mathrm{E}$ and $\mathrm{F})$. Data represent gene expression profiles of PMNL/Mac of 5 mice per treatment $(\mathrm{n}=5)$. Data were analyzed through 2 -way ANOVA with a Tukey's posttest. Significance was considered at ${ }^{*} P<0.05 ;{ }^{*} P<0.005,{ }^{*} * * * P<0.0001$. Differences between columns are indicated with line and asterisk. Error bars represent SEM. 
et al. (2005) described Dex-induced suppression of LPS-dependent inflammatory gene responses in murine macrophages, suggesting a role for GR cross regulation of TLR-dependent genes. In fact, Ogawa et al. (2005) found that GR-suppression of LPS-induced genes in murine macrophages was interferon regulatory factor 3 (IRF3)-dependent, inhibiting nuclear factr NF-kappa-B p65 subunit (p65) and IRF3 interaction; TLR4 can induce IRF3 activation through TRIF- or MyD88-dependent pathways, but TLR4-induction of NF- $\kappa \mathrm{B}$ is solely through MyD88 pathways (Ogawa et al., 2005). Therefore, using MyD88 KO mice, researchers confirmed that GR-suppression of LPS-upregulated genes was IRF3-dependent. Taken together with our model, LPS significantly induced L-selectin and CCL5 expression in WT PMNL/Mac as compared with LPS induction in immunosuppressed WT PMNL/Mac (Figure 4B-C). However, LPS did not significantly induce L-selectin or CCL5 expression in MyD88 KO PMNL/Mac as compared with LPS induction in immunosuppressed MyD88 KO PMNL, suggesting that LPS-induced L-selectin and CCL5 expression in PMNL and Mac may be MyD88-dependent. Future research needs to determine if IRF3 is the transcription factor that inhibits TLR-induced gene expression during Dex treatment.

Our data indicated that OMN supplementation in the diet of WT mice restored ability of PMNL to respond to LPS and express L-selectin and CCL5 (Figure 4). These data agree with Wang et al. (2004), who indicated that OMN restores L-selectin and IL-1 $\beta$ expression in Aspergillus fumigatus-challenged sheep. However, their model demonstrated that $A$. fumigatus, recognized mainly by TLR2 (Mambula et al., 2002), would activate NF-אB to induce inflammatory responses, whereas Ogawa et al. (2005) determined that GR-induced suppression of TLR-induced genes occurs mainly through transcription factor IRF3. Their findings indicate the potential for OMN to regulate transcription factors other than GR-regulated IRF3 and a potential effect in grampositive pathogen infections.

We concluded that MyD88-dependent signaling pathways play a role in OMN restoration of the immunosuppressive effects of Dex on certain PMNL- and Mac-expressed immune genes. Our model investigated TLR4 MyD88-dependent responses in PMNL, indicating that our data can be applied to gram-negative pathogen infections. Additional studies are required to determine the roles of OMN and MyD88 in PMNL phagocytosis and bactericidal activity during conditions of immunosuppression. Future research needs to determine which TLR are involved in OMN restoration of immune responses, which transcription factors are involved downstream in specific pathogen challenges, and the biochemical properties of the additive that restores gene expression. These types of studies will further support use of this product to help ameliorate diseases ailing immune-deficient animals.

\section{ACKNOWLEDGMENTS}

Funding was provided by Phibro Animal Health Corporation (Teaneck, NJ).

\section{REFERENCES}

Burton, J. L., M. E. Kehrli Jr., S. Kapil, and R. L. Horst. 1995. Regulation of L-selectin and CD18 on bovine neutrophils by glucocorticoids: Effects of cortisol and dexamethasone. J. Leukoc. Biol. 57:317-325.

Burton, J. L., S. A. Madsen, L. C. Chang, P. S. Weber, K. R. Buckham, R. van Dorp, M. C. Hickey, and B. Earley. 2005. Gene expression signatures in neutrophils exposed to glucocorticoids: A new paradigm to help explain "neutrophil dysfunction" in parturient dairy cows. Vet. Immunol. Immunopathol. 105:197-219.

Cai, T. Q., P. G. Weston, L. A. Lund, B. Brodie, D. J. McKenna, and W. C. Wagner. 1994. Association between neutrophil functions and periparturient disorders in cows. Am. J. Vet. Res. 55:934-943.

Glass, C. K., and S. Ogawa. 2006. Combinatorial roles of nuclear receptors in inflammation and immunity. Nat. Rev. Immunol. 6:44-55.

Jacob, S. K., V. Ramnath, P. T. Philomina, K. V. Raghunandhanan, and A. Kannan. 2001. Assessment of physiological stress in periparturient cows and neonatal calves. Indian J. Physiol. Pharmacol. 45:233-238.

Mambula, S. S., K. Sau, P. Henneke, D. T. Golenbock, and S. M. Levitz. 2002. Toll-like receptor (TLR) signaling in response to $\mathrm{As}$ pergillus fumigatus. J. Biol. Chem. 277:39320-39326.

Nace, E. L., S. C. Nickerson, F. M. Kautz, S. Breidling, D. Wochele, L. O. Ely, and D. J. Hurley. 2014. Modulation of innate immune function and phenotype in bred dairy heifers during the periparturient period induced by feeding an immunostimulant for 60 days prior to delivery. Vet. Immunol. Immunopathol. 161:240-250.

Ogawa, S., J. Lozach, C. Benner, G. Pascual, R. K. Tangirala, S. Westin, A. Hoffmann, S. Subramaniam, M. David, M. G. Rosenfeld, and C. K. Glass. 2005. Molecular determinants of crosstalk between nuclear receptors and toll-like receptors. Cell 122:707-721.

Preisler, M. T., P. S. Weber, R. J. Tempelman, R. J. Erskine, H. Hunt, and J. L. Burton. 2000. Glucocorticoid receptor down-regulation in neutrophils of periparturient cows. Am. J. Vet. Res. 61:14-19.

Rowson, A. D., Y. Q. Wang, E. Aalseth, N. E. Forsberg, and S. B. Puntenney. 2011. Effects of an immunomodulatory feed additive on the development of mastitis in a mouse infection model using four bovine-origin isolates. Animal 5:220-229.

Ryman, V. E., S. C. Nickerson, F. M. Kautz, D. J. Hurley, L. O. Ely, Y. Q. Wang, and N. E. Forsberg. 2013. Effect of dietary supplementation on the antimicrobial activity of blood leukocytes isolated from Holstein heifers. Res. Vet. Sci. 95:969-974.

Wang, Y., S. B. Puntenney, J. L. Burton, and N. E. Forsberg. 2007. Ability of a commercial feed additive to modulate expression of innate immunity in sheep immunosuppressed with dexamethasone. Animal 1:945-951.

Wang, Y.-Q., S. B. Puntenney, and N. E. Forsberg. 2004. Identification of the mechanisms by which Omnigen-AF, a nutritional supplement, augments immune function in ruminant livestock. Pages 349-352 in Proc. Am. Soc. Anim. Sci. West. Sect. vol. 55. Am. Soc. Anim. Sci., Champaign, IL.

Wang, Y. Q., S. B. Puntenney, J. L. Burton, and N. E. Forsberg. 2009. Use of gene profiling to evaluate the effects of a feed additive on immune function in periparturient dairy cattle. J. Anim. Physiol. Anim. Nutr. (Berl.) 93:66-75. 